\title{
Simulation analysis of the effects of methanol-polyoxymethylene dimethyl ethers blends on combustion and emissions of a PCCI engine
}

\author{
Qian $\mathrm{Ji}^{1^{*}}$, Jie $\mathrm{Li}^{1}$, Jingshan Wang ${ }^{2}$, Ping Sun ${ }^{1}$ and Pengcheng $\mathrm{Wu}^{1}$ \\ ${ }^{1}$ School of Automotive and Traffic Engineering, Jiangsu University, Zhenjiang 212013, China \\ ${ }^{2}$ Science Research Institute, Weichai Power Co., Ltd, Weifang 261061, China
}

\begin{abstract}
The effects of methanol/polyoxymethylene dimethyl ethers (PODE) mixture with different blending ratios on premixed charge compression ignition (PCCI) combustion and emission performance have been researched through the anlysis of CFD software CONVERGE. Premixed combustion is achieved by a single early injection of fuel into the cylinder. The results show that the combustion start point delays and the peak pressure decreases with the increase of methanol blend ratio. The effects of injection timing on the combustion and emission characteristics of PCCI were studied by using a mixture of the same proportion of methanol. The results show that the advance of injection time leads to more homogeneous mixture and higher peak heat release. But too early injection reduces the temperature in the cylinder and makes the combustion worse, resulting in the increase of $\mathrm{HC}$, soot and $\mathrm{CO}$ emissions. $\mathrm{NO}_{\mathrm{x}}$ emissions decrease with the advance of the injection time.
\end{abstract}

\section{Introduction}

With the development of world economy in recent decades, the scale of world industry has also increased greatly. Therefore, the consumption of energy and environmental pollution is greatly aggravated. Diesel engine is widely used in transportation, construction machinery, generator set and other directions because of its excellent power performance and reliability. The use of diesel engine has brought a lot of exhaust pollution. As shown in figure 1, the range of traditional combustion is able to meet $\mathrm{NO}_{\mathrm{x}}$ and soot generation conditions. In order to reduce diesel emission, scholars have proposed Low Temperature Combustion (LTC) technology, including, Homogeneous Charge Compressed Ignition (HCCI) and Premixed Charge Compressed Ignition (PCCI) [1].

Tomohiro et al. [2] implemented PCCI combustion on a diesel engine through early fuel injection to reduce the soot emissions and high EGR rate was adopted to reduce $\mathrm{NO}_{\mathrm{x}}$ emissions. A large number of scholars have researched on LTC model fuels from the perspectives of fuel allocation and blending. Polyoxymethylene dimethyl ethers (PODE) can provide oxygen and reduce soot emissions significantly. Methanol is similar to PODE in calorification value, but has a high latent heat of vaporization. Park et al. [3] showed experimentally that the formation of soot precursors decreases with increased oxygen content and decreased number of $\mathrm{C}-\mathrm{C}$ bonds in the fuel.

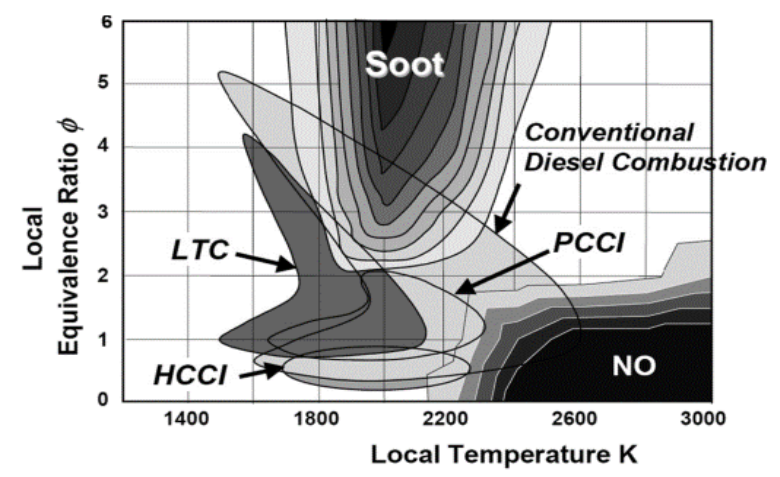

Figure 1. Comparison of traditional and LTC combustion methods.

\section{Computational model and model validation}

\subsection{Computational model}

In this paper, CONVERGE is used for simulation analysis. The RNG k- $\varepsilon$ turbulence model, the KH-RT spray breakup model, the Frossling evaporation model, the Wallfilm impingement model, Zeldovich's $\mathrm{NO}_{\mathrm{x}}$ emission model and Hiroyasu's soot emission model are used in the computational model, and the combustion model uses the SAGE detailed Chemical Reaction Mechanism solver provided by CONVERGE, which can simulate all kind of reaction mechanism in combination with the reaction mechanism. In the simulation analysis process, the inlet

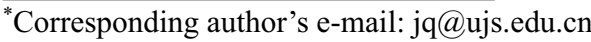


valve closing time $\left(141^{\circ} \mathrm{CA} \mathrm{BTDC}\right)$ to the exhaust valve opening time $\left(139^{\circ} \mathrm{CAATDC}\right)$ were used as the simulation calculation interval. The model grid is automatically generated by the software. The initial pressure is set to 1.97 MPA and the oil temperature is set to $341 \mathrm{~K}$. Some initial boundary conditions that cannot be directly measured by experiments are set according to empirical values. The initial temperature inside the cylinder is set at $355 \mathrm{~K}$, the temperature of cylinder wall is set at $433 \mathrm{~K}$, the temperature of cylinder head is set at $523 \mathrm{~K}$, and the temperature of piston is set at $553 \mathrm{~K}$. The EGR rate is set

Table 1. Physical and chemical properties of methanol and PODE.

\begin{tabular}{ccc}
\hline Parameters & methanol & PODE \\
\hline Density $/\left(\mathrm{kg} \cdot \mathrm{m}^{-3}\right)$ & 796 & 1024 \\
Oxygen Mass Fraction $/ \%$ & 50 & 47.1 \\
Cetane number & 3 & 78 \\
Low calorific value $/\left(\mathrm{MJ} \cdot \mathrm{kg}^{-1}\right)$ & 19.66 & 19.1 \\
latent heat of vaporization $/\left(\mathrm{kJ} \cdot \mathrm{kg}^{-1}\right)$ & 1109 & 330 \\
\hline
\end{tabular}

\subsection{Model validation}

The test engine is a four-cylinder supercharged and intercooled electronically controlled common rail diesel engine. Methanol and PODE were blended into fuel with a volume ratio of 1:9(M10P90). The fuel was injected into the cylinder at $6.5^{\circ} \mathrm{CA}$ before top dead center. The test was carried out under the conditions of average indicating pressure $p_{m i}=0.65 \mathrm{MPa}$ and rotating speed $\mathrm{n}=1540$ $\mathrm{r} / \mathrm{min}$. As shown in figure 2 , the simulated pressure curves are compared with the experimental results. The simulated values are close to the measured ones with an error of less than $5 \%$. Because the cylinder pressure curve is mainly affected by many factors such as cylinder compression, fuel injection and combustion in the cylinder, which is a comprehensive reflection of the above process, it can be proved that the design of the simulation combustion chamber and the selection of the calculation model are reasonable, the model can be used to simulate the combustion characteristics of PCCI with different mixing ratios of methanol and PODE and different injection timing schemes, and analyze the generation characteristics of the emission products. at $40 \%$

\subsection{Physical and chemical properties and Reaction Mechanism of test fuel}

Physical and chemical properties of methanol and PODE are shown in Table 1 [4]. The detailed parameters and reaction mechanism of methanol and PODE are based on the results of previous research.

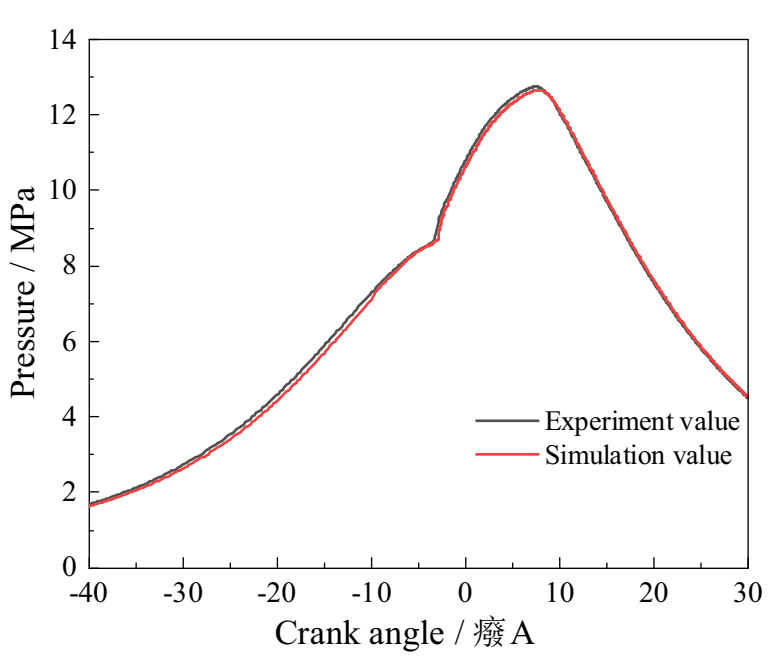

Figure 2. Simulation and experiment values of cylinder pressure.

\section{Analysis of simulation results}

\subsection{Effect of methanol blending ratio on $\mathrm{PCCl}$ emission performance}

Figure 3 shows the impact of different methanol ratios in blended fuels on PCCI emission performance. It can be seen from the figure 3, under the same injection timing, soot, $\mathrm{HC}$ and $\mathrm{CO}$ emissions also increase gradually with the increase of methanol mixing proportion. Since the latent heat of methanol vaporization is high, the increase of methanol ratio will lead to the decrease of combustion temperature and the combustion deterioration. Since the delay of the start of combustion increases the mixing time, and the high latent heat of methanol decreases the temperature, $\mathrm{NO}_{\mathrm{x}}$ emission decreases with the increase of methanol proportion. 


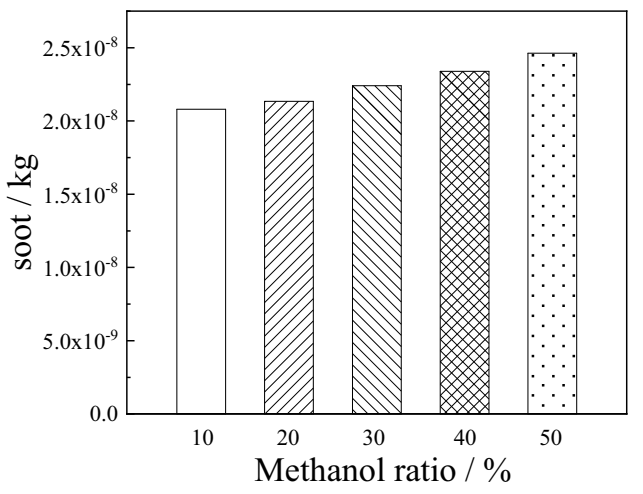

(a)soot

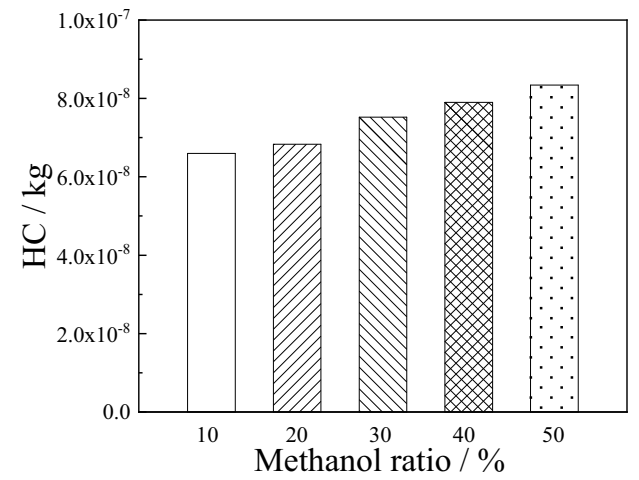

(c) $\mathrm{HC}$

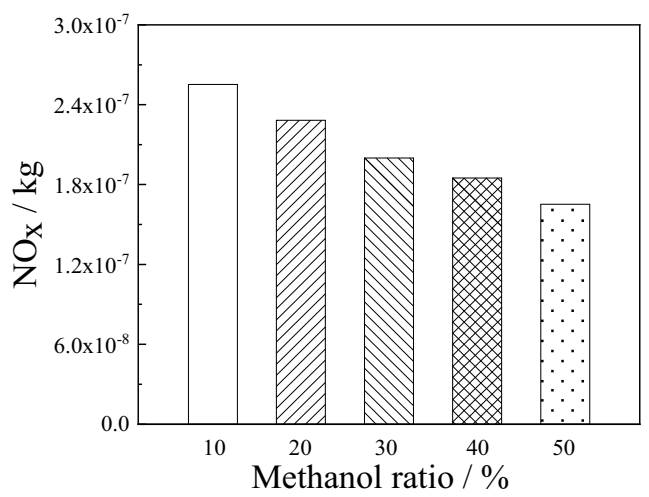

(b) $\mathrm{NO}_{x}$

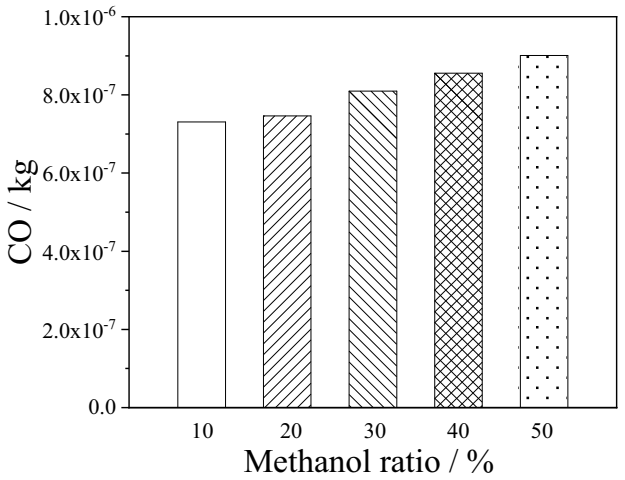

(d) $\mathrm{CO}$

Figure 3. Effects of methanol ratio on PCCI emission performance.

\subsection{Effects of injection timing on combustion performance of $\mathrm{PCCl}$}

Figure 4 shows the changes of the in-cylinder pressure and the instantaneous heat release with the change of injection timing. With the advance of the injection time, the cylinder pressure curves gradually increase. The exothermic peak gradually moves forward, and the exothermic peak also gradually increases. Because of the advance of fuel injection time, fuel and air mixing time increase, the amount of fuel in the cylinder increases relatively, the ignition time advance.

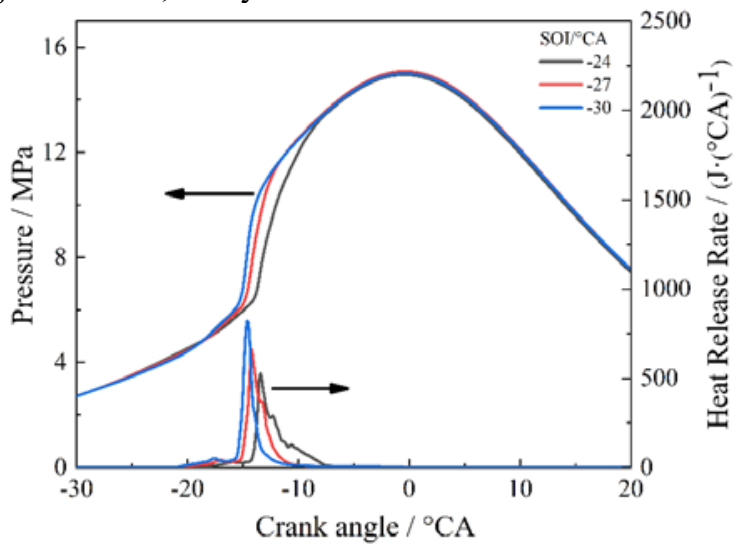

Figure 4. Effects of injection timing on combustion performance of PCCI.

Figure 5 shows the distribution of temperature and equivalent ratio in the same crankshaft Angle cylinder when the injection timing is changed. With the advance of injection time, the temperature in the cylinder is higher, which proves that the combustion starting point is advanced. Because of the early injection, piston has not yet risen to a sufficient height, so part of the fuel has not been injected into the pit of the piston. Because of insufficient fluidity resulting in insufficient combustion, there will still be areas with high equivalence ratio in the combustion chamber. 


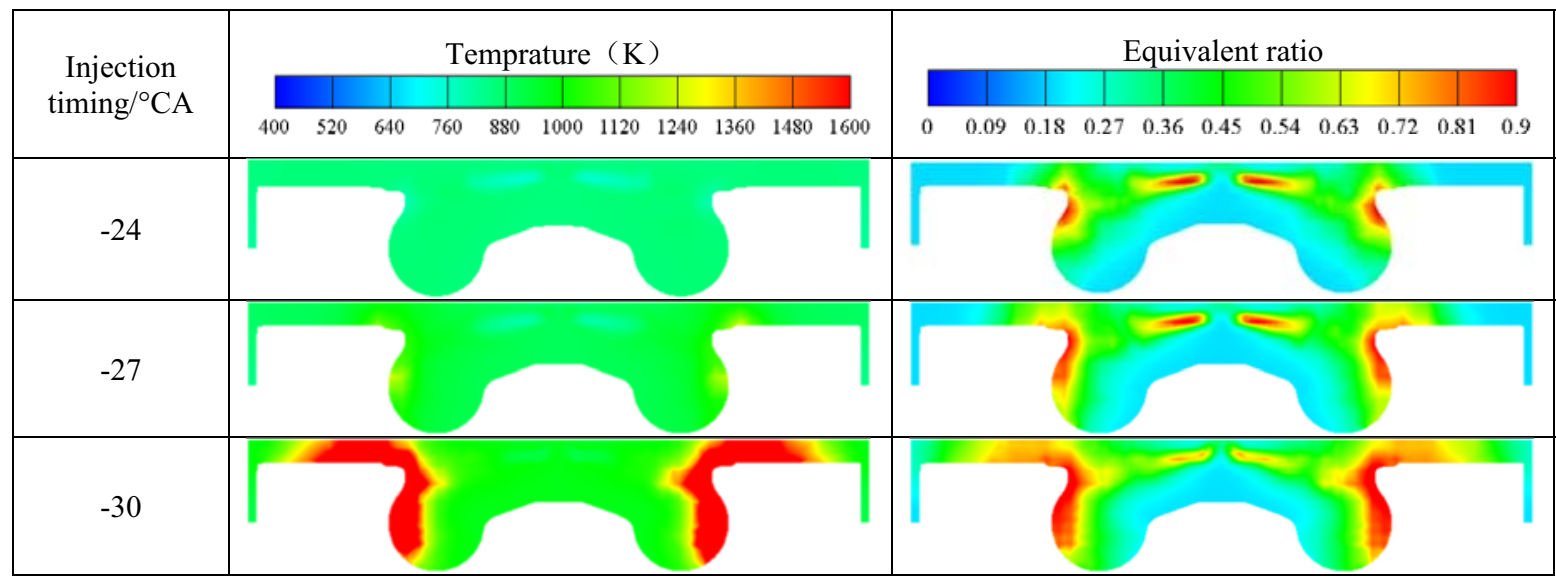

(a) Crank angle $15^{\circ} \mathrm{CA} \mathrm{BTDC}$

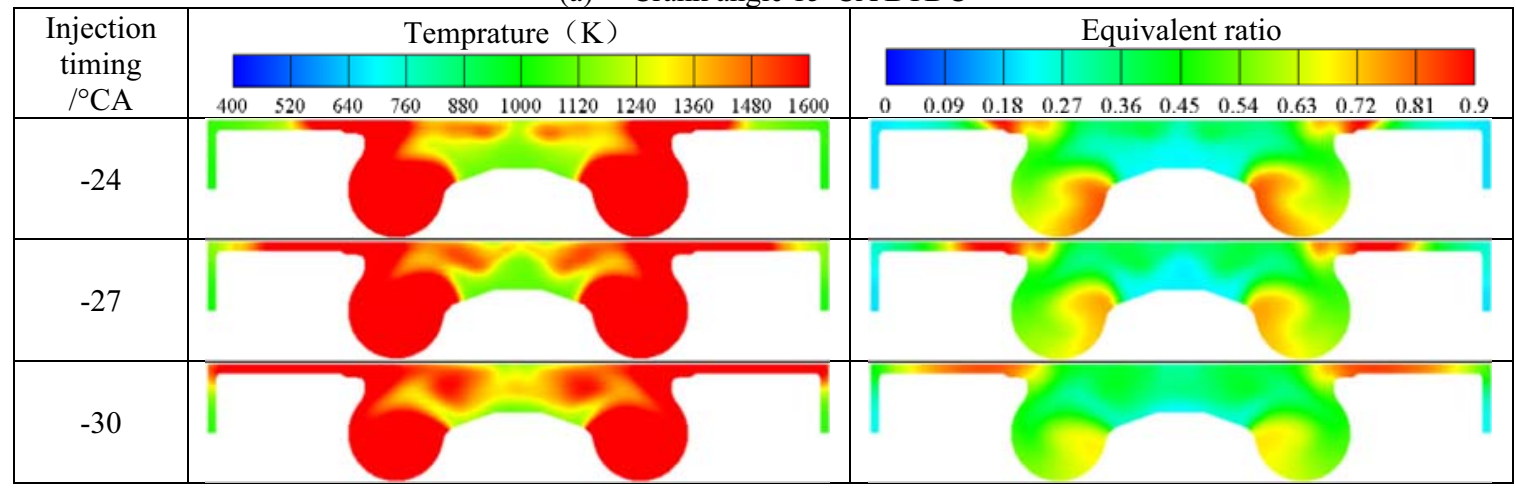

(b) Crank angle $1^{\circ} \mathrm{CA}$ BTDC

Figure 5. Effects of injection timing on temperature and equivalent ratio.

\subsection{Effect of injection timing on $\mathrm{PCCl}$ emission performance}

Figure 6 shows the effect of injection timing on PCCI emissions. With the advance of the injection time, the mixture is more uniform, the combustion duration is

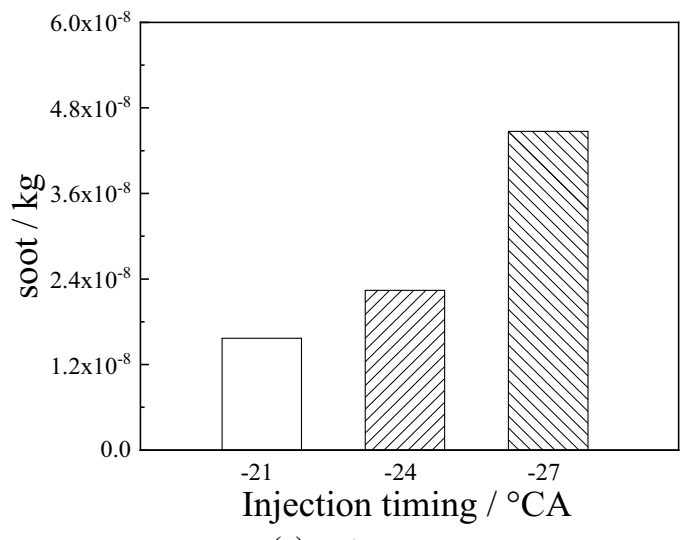

(a)soot shortened, the low temperature combustion is more obvious, and the $\mathrm{NO}_{\mathrm{x}}$ emission is reduced gradually. As the temperature in the cylinder decreases, combustion deterioration will also increase the emissions of $\mathrm{HC}, \mathrm{CO}$ and soot.

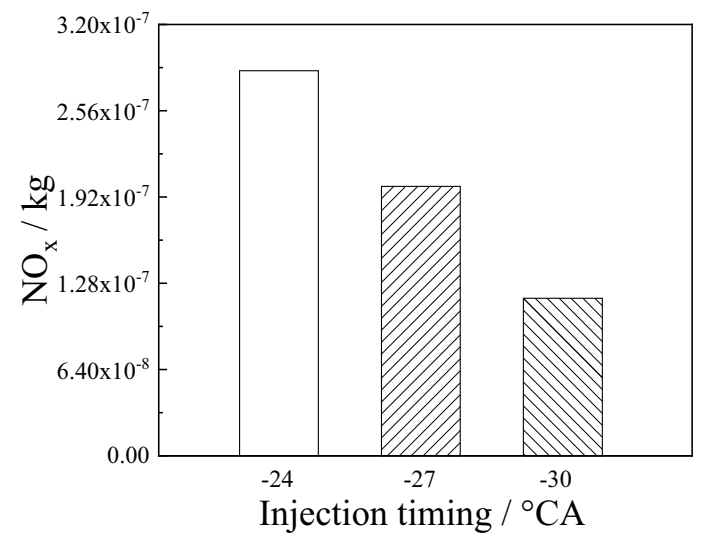

(b) $\mathrm{NO}_{\mathrm{x}}$ 


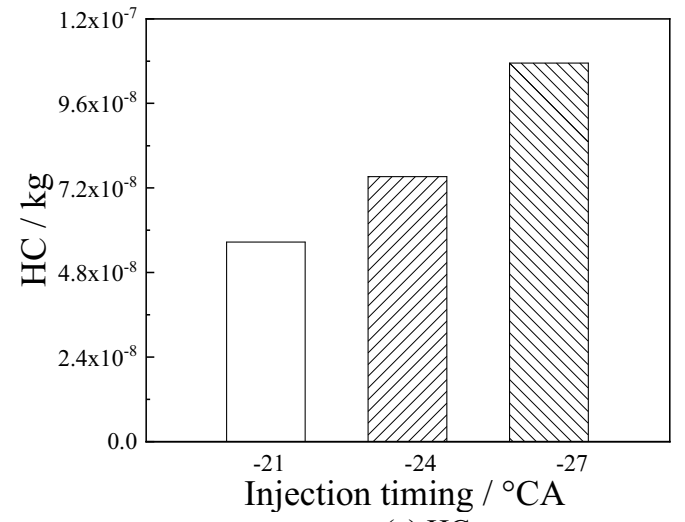

(c) $\mathrm{HC}$

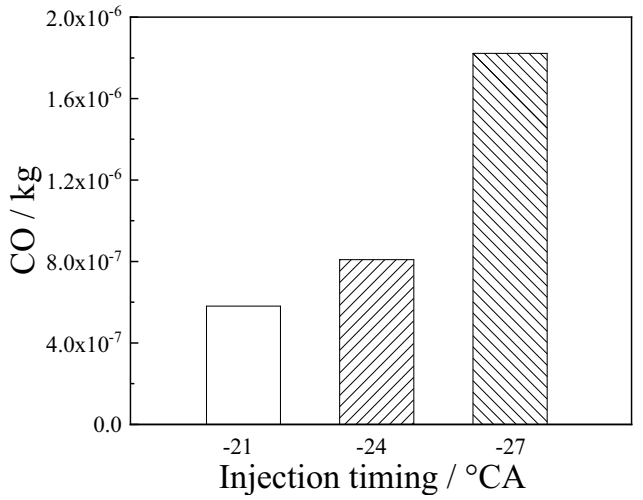

(d) $\mathrm{CO}$

Figure 6. Effects of methanol blending ratio on PCCI emission performance.

\section{Conclusion}

In this paper, the effects of methanol blending ratio and injection time on the combustion and emission characteristics of PCCI are analyzed by simulation. The conclusions are as follows:

(1) With the increase of methanol blending ratio, the temperature in cylinder decreases and the peak pressure in cylinder decreases.

(2) The increase of methanol ratio results in the increase of soot, $\mathrm{HC}$ and $\mathrm{CO}$ emissions and the decrease of $\mathrm{NO}_{\mathrm{x}}$ production.

(3) The advance of injection time results in the increase of $\mathrm{HC}, \mathrm{CO}$ and soot emissions and the decrease of $\mathrm{NO}_{\mathrm{x}}$ emissions.

\section{Acknowledgments}

This work was supported by the project funded by China Postdoctoral Science Foundation (No. 2020M672133).

\section{References}

1. Das, P., Subbarao, P.M.V., Subrahmanyam, J.P. (2015) Effect of main injection timing for controlling the combustion phasing of a homogeneous charge compression ignition engine using a new dual injection strategy $[\mathrm{J}]$. Energy Conversion and Management, 95: 248-258.

2. Tomohiro, K., Hakozaki, T., Uchimoto, T. (2005) PCCI operation with early injection of conventional diesel fuel [C]. SAE Paper 2005-01-0378.

3. Park, W., Park, S., Reitz, R.D., Kurtz, E. (2017) The effect of oxygenated fuel properties on diesel spray combustion and soot formation. Combust Flame, 180:276-83.

4. Zhang, Z.H., Tsang, K.S., Cheung, C.S. (2011) Effect of fumigation methanol and ethanol on the gaseous and particulate emissions of a direct-injection diesel engine [J]. Atmospheric Environment, 45(11): 20012008. 